\title{
Sexual Differences in the Diameter of Coronary Arteries in an Adult Sri Lankan Population
}

\author{
Diferencias Sexuales en el Diámetro de las Arterias Coronarias en una Población Adulta de Sri Lanka
}

\author{
I. Ilayperuma; B. G. Nanayakkara \& K. N. Palahepitiya
}

ILAYPERUMA, I.; NANAYAKKARA, B. G. \& PALAHEPITIYA, K. N. Sexual differences in the diameter of coronary arteries in an adult Sri Lankan population. Int. J. Morphol., 29(4):1444-1448, 2011.

SUMMARY: Coronary artery disease is a major cause of human mortality. It is stated that females have worse outcomes than men following myocardial infarction and coronary revascularization. Sexual differences in the coronary artery diameters have also been speculated as one of the reasons for the above outcome. However, because of possible confounding effects, such as the body size and heart weight, it is unclear if there is a true sex-specific effect on coronary arterial size. The present study was undertaken to investigate the sexual differences in the diameter of coronary arteries in a group of adult Sri Lankan population. The diameters of the coronary arteries and their branches were measured at predetermined sites in a total of one hundred and two apparently healthy hearts obtained from cadavers during routine gross anatomy dissections. All measurements were taken using a digital sliding caliper capable of measuring to the nearest $0.01 \mathrm{~mm}$. The mean coronary arterial diameters were significantly smaller in females than in males. These differences persisted even after the diameters of coronary arteries were corrected for heart weight and body surface areas. Precise knowledge of the expected normal coronary arterial diameter at a given anatomic location is the first step towards developing a quantitative estimate of the severity of the coronary artery disease. This study provides a reference data set for adult Sri Lankans against which to compare the diameters of coronary arteries in various pathological conditions.

KEY WORDS: Coronary artery; Sri Lankan; Sexual differences.

\section{INTRODUCTION}

Arterial blood supply to the heart is by two coronary arteries and their branches. The right and left coronary arteries arise from the aortic sinus at the beginning of the ascending aorta and then descend in the right and left atrioventricular grooves respectively. The anterior interventricular and circumflex arteries are the main branches of the left coronary artery whereas marginal and posterior interventricular arteries arise from the right coronary artery (Williams et al., 2000).

It is often stated that females have worse outcomes than men following a myocardial infarction and coronary revascularization. The reasons for the above differences are likely to be of multifactorial origin, including the differences in size of the coronary arteries (Vaccarino et al., 1995; Eaker et al., 1989). There is evidence linking smaller dimensions of the coronary arteries to adverse cardiovascular events. For instance, in percutaneous revascularization, coronary arterial diameter is a strong predictor of restenosis (Mintz et al., 1996). Furthermore, in coronary artery bypass surgery, target vessel size correlates with long term graft patency (Fisher et al., 1982). It is also known that in atherosclerotic plaque rupture, smaller lumen diameter increases the risk of total occlusion and myocardial infarction (Fuster et al., 1992).

Several methods, such as, angiography, autopsy studies, intravascular ultrasound, have been occupied by various investigators to study the potential relation between the coronary artery dimensions and sex differences in prognosis of the coronary artery disease (Dodge et al., 1992; Roberts \& Roberts, 1980; MacAlpin et al., 1973). However, it remains unclear whether sex differences in arterial dimensions simply reflect the effects of differences in body size or whether they are true sex-specific traits.

Precise knowledge of the expected normal coronary arterial diameter at a given anatomic location is the first step 
towards developing a quantitative estimate of the severity of the coronary artery disease. Therefore, the present study was undertaken to investigate the sexual differences in the diameter of coronary arteries in a group of adult Sri Lankan population. Such data will be of immense use in the understanding of sexual differences in coronary artery disease.

\section{MATERIAL AND METHOD}

This study was carried out on one hundred and two apparently healthy human hearts obtained from cadavers (68 male and 34 female) during routine gross anatomy dissections in the Department of Anatomy, Faculty of Medicine, University of Ruhuna, Galle, Sri Lanka. The cadavers were preserved in formalin for a variable period of time (3 months -1 year). The age group of the cadavers varied between 48-67 years. Hearts weighing more than $370 \mathrm{~g}$ in males and $280 \mathrm{~g}$ in females were excluded from the study to avoid the possibility of hypertensive cases. The height and the weight of the cadavers as well as the weights of the hearts were recorded. The chambers of the hearts were open and blood clots were removed before recording the weights of the hearts. Body surface areas were calculated using the method described by Dubois \& Dubois in 1916 (DuBois \& DuBois, 1989).

The external diameters of the coronary arteries were measured at the following predetermined sites:

(i) Right coronary artery at its origin

(ii) Right coronary artery $2.5 \mathrm{~cm}$ away from the origin

(iii) Left coronary artery at its origin

(iv) Anterior interventricular artery $5 \mathrm{~mm}$ away from its origin

(v) Circumflex artery $5 \mathrm{~mm}$ away from its origin
The diameters were recorded using a digital sliding caliper (Mitutoyo, Japan) capable of measuring to the nearest $0.01 \mathrm{~mm}$. All the measurements were repeated thrice by the same person and the mean was taken for further analysis.

Results were expressed as mean \pm SD. Statistical analysis was performed using the $t$ test. $P$ value $<0.05$ was considered statistically significant. To determine whether sex differences in coronary artery diameters are manifestations of differences in body size and heart weight, each measurement was divided by body surface area (BSA) and heart weight respectively and $t$ test was repeated for the corrected values.

\section{RESULTS}

Demographic characteristics of the male and female study group are presented in Table I. The mean age, body weight and heart weights were not significantly different between the sexes. The mean height and body surface area were significantly smaller in females than in males.

Mean coronary arterial diameters are presented in Table II and Figure 1. There was a definite trend in coronary artery diameters. Females showed a significantly smaller arterial diameters in both right and left coronary arteries compared to that of the males $(\mathrm{P}<0.05)$. Female coronary arterial diameters of the anterior interventricular and circumflex arteries were also smaller than that of the males although the differences were not statistically significant between the sexes $(\mathrm{P}>0.05)$.

Mean coronary arterial diameters after adjusting for body surface area and heart weight are presented in Tables III and IV respectively. Females demonstrated smaller coronary arterial diameters than males even after normalization for body surface area and heart weight.

Table I. Characteristics of the study population.

\begin{tabular}{lcc}
\hline Characteristic & Male & Female \\
\hline Age $(\mathrm{yrs})$ & $57.5 \pm 12.5$ & $57.0 \pm 10.8$ \\
Height $(\mathrm{cm})$ & $160.88 \pm 4.22 *$ & $139.5 \pm 10.47$ \\
Heart weight $(\mathrm{g})$ & $183.78 \pm 68.29$ & $150.69 \pm 65.87$ \\
Body weight $(\mathrm{Kg})$ & $44.63 \pm 7.52$ & $40.25 \pm 7.41$ \\
Body surface area $\left(\mathrm{Kg} / \mathrm{cm}^{2}\right)$ & $1.430 \pm 0.10^{*}$ & $1.238 \pm 0.14$ \\
Heart weight/body weight & $4.134 \pm 1.394$ & $3.757 \pm 1.566$ \\
Heart weight/body surface area & $128.34 \pm 46.572$ & $120.74 \pm 47.606$ \\
\hline
\end{tabular}

$*(\mathrm{P}<0.05)$ 
Table II. Coronary artery diameters.

\begin{tabular}{lcc}
\hline Coronary artery & Diameter (Male) & Diameter (Female) \\
\hline Right coronary artery at its origin & $5.99 \pm 1.23^{*}$ & $4.73 \pm 1.82$ \\
Right coronary artery $2.5 \mathrm{~cm}$ aw ay from the origin & $5.28 \pm 1.45^{*}$ & $4.32 \pm 1.92$ \\
Left coronary artery at its origin & $4.79 \pm 1.06^{*}$ & $4.12 \pm 0.77$ \\
Anterior interventricular artery 5 mm way from its origin & $3.96 \pm 0.99$ & $3.72 \pm 1.18$ \\
Circumflex artery $5 \mathrm{~mm}$ away from its origin & $3.94 \pm 1.34$ & $3.725 \pm 0.78$
\end{tabular}

$*(\mathrm{P}<0.05)$

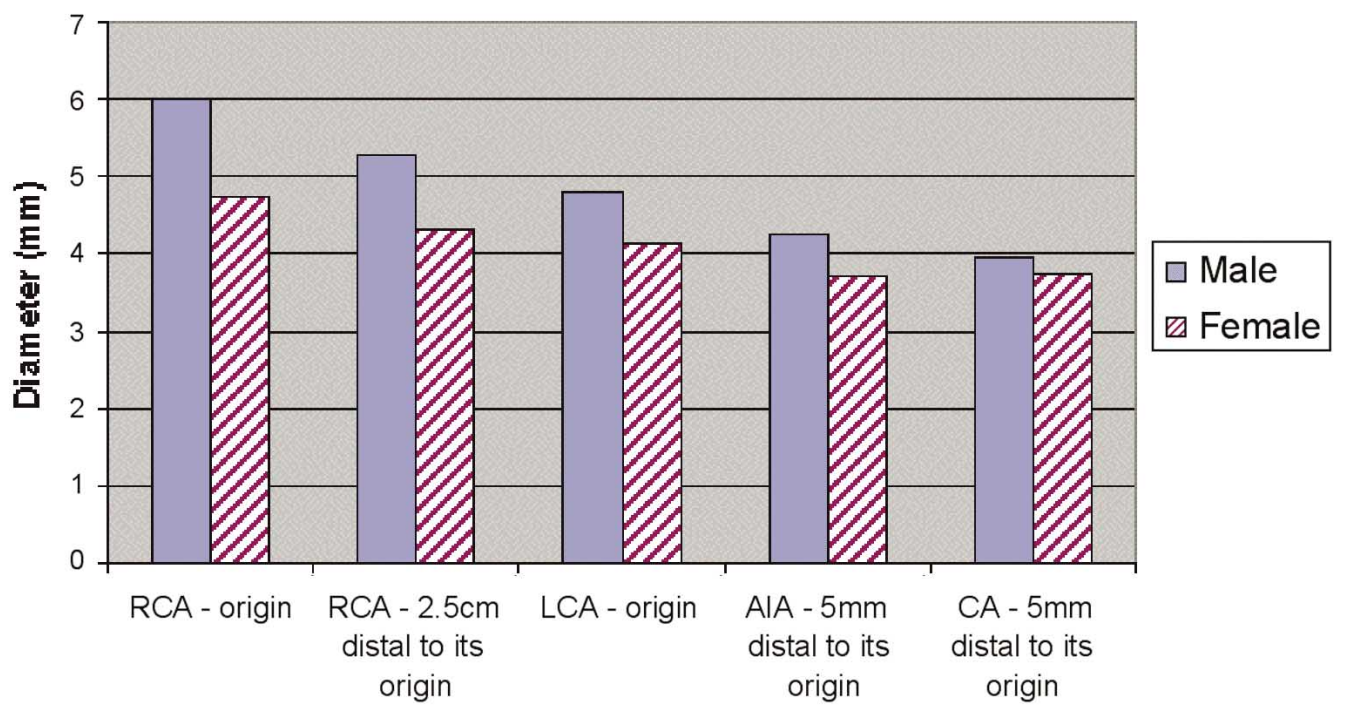

Coronary arteries

Fig. 1. Bar chart demonstrating the coronary artery diameters in males and females. RCA - Right coronary artery, LCA - Left coronary artery, AIA - Anterior interventricular artery and CA - Circumflex artery.

Table III. Coronary artery diameters corrected for body surface area.

\begin{tabular}{lcc}
\hline Coronary artery & Diameter (Male) & Diame ter (Female) \\
\hline Right coronary artery at its origin & $4.21 \pm 0.94$ & $3.79 \pm 1.34$ \\
Right coronary artery $2.5 \mathrm{~cm}$ aw ay from the origin & $3.72 \pm 1.09$ & $3.45 \pm 1.44$ \\
Left coronary artery at its origin & $3.37 \pm 0.77$ & $3.38 \pm 0.81$ \\
Anterior interventricular artery $5 \mathrm{~mm}$ away from its origin & $2.79 \pm 0.81$ & $3.11 \pm 1.30$ \\
Circumflex artery $5 \mathrm{~mm}$ away from its origin & $2.79 \pm 1.07$ & $3.07 \pm 0.87$ \\
\hline
\end{tabular}

Table IV. Coronary artery diameters corrected for heart weight.

\begin{tabular}{lcc}
\hline Coronary artery & Diameter (Male) & Diameter (Female) \\
\hline Right coronary artery at its origin & $0.037 \pm 0.016$ & $0.032 \pm 0.005$ \\
Right coronary artery 2.5 cm away from the origin & $0.032 \pm 0.015$ & $0.029 \pm 0.006$ \\
Left coronary artery at its origin & $0.029 \pm 0.011$ & $0.031 \pm 0.014$ \\
Anterior interventricular artery 5 mm away from its origin & $0.024 \pm 0.010$ & $0.030 \pm 0.018$ \\
Circumflex artery 5 mm away from its origin & $0.025 \pm 0.012$ & $0.029 \pm 0.013$ \\
\hline
\end{tabular}




\section{DISCUSSION}

This study highlights the sexual dimorphism in coronary arterial diameters in a group of adult Sri Lankans. There was a definite trend in the diameters of the coronary arteries, i.e., the diameters were smaller in females compared to males. This result was consistent with the previous findings (Dodge et al.; Roberts \& Roberts; MacAlpin et al.). It has been shown previously that the diameters of the coronary arteries are not affected by the age or the vessel tortuosity (Dodge et al.).

Body surface area and heart weight were shown to have a positive correlation with the size of the coronary arteries (Sheifer et al., 2000). However, results of the current study shows that after correcting for these two factors (body surface area and heart weight), coronary arterial diameters were still smaller in females though they have lost the significant sex differences. This suggests an association between coronary arterial diameter and sex that was independent of body surface area or heart weight. The sexspecific influence on coronary artery size, in turn, provides a possible explanation for the sex differences in coronary outcomes. Our findings are in agreement with results obtained from previous studies on coronary arterial dimensions (Roberts \& Roberts; MacAlpin et al.; Kornowski et al., 1997).

The mechanisms that underlie the sex differences are unknown. It may be attributed to the differences in levels of hormones such as estrogen. Estrogen is known to affect the endothelial function and coronary vasomotion (Gilligan et al., 1994). Identification of specific mechanisms for sex differences in coronary heart disease could lead to the development of novel therapies aimed at increasing the coronary artery size. Given that the size of the coronary arteries has prognostic implications, such therapies may hold the potential to improve outcomes of females with coronary artery disease.

The current study has addressed only the major coronary arteries and proximal parts of their branches. Therefore, conclusions regarding the other branches of the coronary arteries and their distal parts are limited. In addition, this study was also limited by the effect of post mortem changes and lack of history regarding the presence or absence of coronary heart disease of the subjects. Further investigations should be performed to corroborate these findings.

Precise knowledge of the expected normal coronary arterial diameter at a given anatomic location is the first step towards developing a quantitative estimate of the severity of the coronary artery disease. This study provides a reference data set against which to compare the diameters of coronary arteries in various pathological conditions.

ILAYPERUMA, I.; NANAYAKKARA, B. G. \& PALAHEPITIYA, K. N. Diferencias sexuales en el diámetro de las arterias coronarias en una población adulta de Sri Lanka. Int. J. Morphol., 29(4):1444-1448, 2011.

RESUMEN: La enfermedad coronaria es la mayor causa de mortalidad humana. Se afirma que las mujeres tienen peores resultados que los hombres después de un infarto de miocardio y revascularización coronaria. Diferencias sexuales en los diámetros de las arterias coronarias han sido especuladas como una de las razones para los resultados anteriores. Sin embargo, debido a posibles efectos de confusión, tales como talla corporal y peso del corazón, no está claro si hay un verdadero efecto sexo-específico sobre el tamaño arterial coronario. El presente estudio se realizó para investigar las diferencias sexuales en el diámetro de las arterias coronarias en un grupo de adultos de la población de Sri Lanka. Los diámetros de las arterias coronarias y sus ramas se midieron en lugares predeterminados en un total de 102 corazones aparentemente sanos obtenidos de cadáveres durante las disecciones anatómicas de rutina. Todas las medidas fueron tomadas con un caliper digital deslizante (precisión 0,01 mm). La media del diámetro arterial coronario fue significativamente menor en mujeres que en hombres. Estas diferencias persisten aún después de que los diámetros de las arterias coronarias fueron corregidos por el peso del corazón y talla corporal. El conocimiento preciso del diámetro de la arteria coronaria normal esperado en un determinado lugar anatómico es el primer paso hacia el desarrollo de una estimación cuantitativa de la gravedad de la enfermedad de las arterias coronarias. Este estudio proporciona un conjunto de datos de referencia para adultos de Sri Lanka con el cual comparar los diámetros de las arterias coronarias en diversas condiciones patológicas.

PALABRAS CLAVE: Arteria coronaria; Sri Lanka; Diferencias sexuales.

\section{REFERENCES}

Dodge, J. T. Jr.; Brown, B. G.; Bolson, E. L. \& Dodge, H. T. Lumen diameter of normal human coronary arteries. Influence of age, sex, anatomic variation, and left ventricular hypertrophy or dilation. Circulation, 86(1):232-46, 1992. 
Du Bois, D. \& Du Bois, E. F. A formula to estimate the approximate surface area if height and weight be known. 1916. Nutrition, 5(5):303-11; discussion 312-3, 1989.

Eaker, E. D.; Kronmal, R.; Kennedy, J. W. \& Davis, K. Comparison of the long-term, postsurgical survival of women and men in the Coronary Artery Surgery Study (CASS). Am. Heart J., 117(1):71-81, 1989.

Fisher, L. D.; Kennedy, J. W.; Davis, K. B.; Maynard, C.; Fritz, J. K.; Kaiser, G. \& Myers, W. O. Association of sex, physical size, and operative mortality after coronary artery bypass in the Coronary Artery Surgery Study (CASS). J. Thorac. Cardiovasc. Surg., 84(3):334-41, 1982.

Fuster, V.; Badimon, L.; Badimon, J. J. \& Chesebro, J. H. The pathogenesis of coronary artery disease and the acute coronary syndromes (2). N. Engl. J. Med., 326(5):310-8, 1992.

Gilligan, D. M.; Quyyumi, A. A. \& Cannon, R. O. 3rd. Effects of physiological levels of estrogen on coronary vasomotor function in postmenopausal women. Circulation, 89(6):2545$51,1994$.

Kornowski, R.; Lansky, A. J.; Mintz, G. S.; Kent, K. M.; Pichard, A. D.; Satler, L. F.; Bucher, T. A.; Popma, J. J. \& Leon, M. B. Comparison of men versus women in cross-sectional area luminal narrowing, quantity of plaque, presence of calcium in plaque, and lumen location in coronary arteries by intravascular ultrasound in patients with stable angina pectoris. Am. J. Cardiol., 79(12):1601-5, 1997.

MacAlpin, R. N.; Abbasi, A. S.; Grollman, J. H. Jr. \& Eber, L. Human coronary artery size during life. A cinearteriographic study. Radiology, 108(3):567-76, 1973.

Mintz, G. S.; Popma, J. J.; Pichard, A. D.; Kent, K. M.; Salter, L. F.; Chuang, Y. C.; Griffin, J. \& Leon, M. B. Intravascular ultrasound predictors of restenosis after percutaneous transcatheter coronary revascularization. J. Am. Coll. Cardiol., 27(7):1678-87, 1996.

Roberts, C. S. \& Roberts, W. C. Cross-sectional area of the proximal portions of the three major epicardial coronary arteries in 98 necropsy patients with different coronary events. Relationship to heart weight, age and sex. Circulation, 62(5):953-9, 1980.

Sheifer, S. E.; Canos, M. R.; Weinfurt, K. P.; Arora, U. K.; Mendelsohn, F. O.; Gersh, B. J. \& Weissman, N. J. Sex differences in coronary artery size assessed by intravascular ultrasound. Am. Heart J., 139(4):649-53, 2000.

Vaccarino, V.; Krumholz, H. M.; Berkman, L. F. \& Horwitz, R. I. Sex differences in mortality after myocardial infarction. Is there evidence for an increased risk for women? Circulation, 91(6):1861-71, 1995.

Williams, P. L.; Bannister, L. H.; Berry, M. M.; Collins, P.; Dyson,
M. \& Dussek, J. E. Gray's Anatomy: The Anatomical Basis of Medicine and Surgery. $38^{\text {th }}$ edition. New York, Churchill Livingstone, 2000.

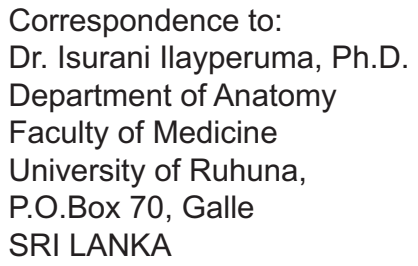

Telephone: 0094-91-2234801

Fax: 0094-91-2222314

Email: iisurani@yahoo.com

Received: 07-05-2011

Accepted: 05-09-2011 